\title{
Effects of Low Pressure Hypoxia on Oxidation - Antioxidant System of Player
}

\author{
Xin Tan \\ Department of Sports and leisure, Sichuan Tourism University, Chengdu, China.
}

Keywords: Volleyball player; Oxidation - Antioxidant system; Low pressure hypoxia; SOD; CAT

\begin{abstract}
Purpose: To study the effect of hypobaric hypoxia on the oxidative-antioxidant system of volleyball players, and to provide a safe and reliable clinical treatment for cardiovascular disease. Method: Eight volleyball athletes trained on low altitude and low oxygen in a plateau on May 12, 2017 were listed as observation group, and 20 athletes trained in normothermic normoxia were selected. ( $\mathrm{P}<0.05$ ). The levels of superoxide dismutase (SOD) and catalase (CAT) in the brain tissue of the two groups were significantly higher than those in the control group $(\mathrm{P}<0.05)$, and the levels of mitochondrial malondialdehyde (MDA) And myocardial mitochondrial free $\mathrm{Ca}^{2+}$ levels. Result: The levels of SOD and CAT in the observation group were lower than those in the control group ( $\mathrm{P}<0.05)$, and the level of SOD and CAT in the observation group was the highest $(\mathrm{P}<0.05)$. The expression of $\mathrm{Cygb}$ in the observation group was higher than that in the control group. The level of Cygb in the observation group was higher than that in the control group $(\mathrm{P}<0.05, \mathrm{t}=$ 2.8676). The myocardial mitochondrial free $\mathrm{Ca} 2+$ level in the observation group was lower than that in the control group, $\mathrm{P}<0.05, \mathrm{t}=5.8190$. Conclusion: Volleyball player's oxidation-oxidation system is related to the generation of oxygen free radicals. It can be judged by monitoring the parameters such as SOD, CAT, Cygb, MDA, ATP, $\mathrm{Ca}^{2+}$ and other indicators in the brain tissue during the daily life signs of athletes. According to the principle of relevance, take CIHH for treatment.
\end{abstract}

\section{Introduction}

In 1956, American scholars put forward the theory of free radical damage, the theory pointed out: "aerobic cell metabolism in the process of superoxide free radicals can cause tissue cell damage and aging[1-4]." Free radicals play an important role in human signal transduction, and once damaged, it is bound to affect gene expression. At the same time, the free radicals of the human body will be a variety of biological macromolecules attack, resulting in lipid peroxidation, DNA damage and other related oxidative damage, and even induced gene mutation, leading to abnormal differentiation of healthy cells into cancer cells. Therefore, maintaining the low concentration of free radicals is the key to avoid the above phenomenon. It is the importance of the presence of antioxidant systems in the human body[5-9]. The antioxidant system can effectively remove free radicals and ensure that free radicals are in the dynamic equilibrium of generation and removal.

However, some studies have shown that low-pressure hypoxia has a significant impact on the body's antioxidant system. To confirm the reliability of this conclusion, 100 volleyball players were selected as the research object. The detailed process is as follows:

\section{Materials and Methods}

\section{General Materials}

80 athletes who were trained in low altitude and low oxygen training on a plateau on May 12, 2017 were listed as observation group. The athletes with low and low oxygen training for 6 hours were classified as observation group ( I ), all female, aged 16-27 (21 \pm 3.0$)$ years old; the low-pressure hypoxia training $12 \mathrm{~h}$ athletes as observation group ( II ), are women, aged 16-28 years, the average age $(21 \pm 3.2)$ years; will be one of the low-pressure The average age $(21 \pm 2.7)$ years was the age of 16-25 years old. The athletes with low-pressure and low-oxygen training were listed as observation group (IV) Female, aged $16-26$ years, mean age $(21 \pm 2.9)$ years old. Each group of 20 
cases. Twenty normal athletes who were trained in normoxic exercise were all female, aged 17-28 years, with an average age of $(22 \pm 2.8)$ years. There was no statistically significant difference between the above groups, which was not statistically significant $(\mathrm{P}>0.05)$.

\section{Method}

SOD was measured by SOD kit; CAT was measured by CAT kit. (The above kit is provided by Jiangsu Baolai Biotechnology Co., Ltd.)

The expression level of Cygb in brain tissue was detected by RT-PCR. The level and completeness of RNA were determined by agarose gel electrophoresis and spectrophotometry. The mitochondrial ultrastructure was observed by JEM1200EX transmission electron microscopy. The mitochondrial ATP levels were measured by biochemical luminescence.

\section{Observe Indicators}

(1) The levels of related molecules in SOD and CAT brain tissues were compared. (2) The expression of Cygb was compared between the two groups. (3) The myocardial mitochondrial MDA levels were compared between the two groups. (4) The myocardial mitochondrial ATP levels were compared between the two groups. (5) Compare the two groups' myocardial mitochondrial free $\mathrm{Ca}^{2}$ ${ }^{+}$levels.

\subsection{Statistical Processing}

The data in the study were expressed as $(\%)$, and the data were calculated by $(\bar{x} \pm s)$ using the statistical software SPSS19.0. The $\chi^{2}$ and t tests were used for the significance test. If the test result was $\mathrm{P}<0.05$, the difference was Statistical significance.

\section{Results}

\section{A Comparison of the Levels of Related Molecules in Brain Tissue of Volleyball Players}

It can be known from statistical comparison that: (1) The levels of SOD and CAT in the observation group were lower than those in the control group, the difference was significant $(\mathrm{P}<0.05)(2)$ The levels of SOD and CAT in the observation group ( I ), ( II ), (III) and (IV) were the highest in the observation group $(\mathrm{P}<0.05)$. See Table 1 for details.

Table 1 A Comparative of the Levels of Related Molecules in Brain Tissue of Volleyball Players

\begin{tabular}{cccc} 
& & $(\bar{x} \pm s)$ & \\
\hline Group & $\begin{array}{c}\text { Number of } \\
\text { cases }\end{array}$ & SOD $(\mathrm{U} / \mathrm{mg})$ & CAT $(\mathrm{U} / \mathrm{g})$ \\
\hline $\begin{array}{c}\text { Control } \\
\text { group }\end{array}$ & 20 & $137.743 \pm 4.889$ & $119.041 \pm 18.948$ \\
$\begin{array}{c}\text { Observatio } \\
\text { n group (I) }\end{array}$ & 20 & $123.416 \pm 9.118$ & $30.155 \pm 3.675$ \\
$\begin{array}{c}\text { Observatio } \\
\text { ngroup } \\
\quad \text { (II) }\end{array}$ & 20 & $114.491 \pm 6.662$ & $21.387 \pm 3.011$ \\
$\begin{array}{c}\text { Observatio } \\
\text { n group } \\
\quad \text { (III) }\end{array}$ & 20 & $105.582 \pm 2.452$ & $16.254 \pm 1.788$ \\
$\begin{array}{c}\text { Observatio } \\
\text { n group } \\
\text { (IV) }\end{array}$ & 20 & $95.541 \pm 6.652$ & $10.329 \pm 2.254$ \\
\hline
\end{tabular}

\section{Comparison of Cygb expression in brain tissue of different volleyball players}

It can be known from statistical comparison that: (1) The expression of Cygb in the observation group was higher than that in the control group, the difference was significant $(\mathrm{P}<0.05)$; (2) The expression of Cygb in the observation group (IV) was the highest in the observation group ( I ), ( II ), (III) and (IV), and the difference was significant ( $\mathrm{P}<0.05)$. See Table 2 for details. 
Table 2 Comparison of Cygb expression in brain tissue of different volleyball players $(\bar{x} \pm s)$

\begin{tabular}{ccc}
\hline Group & Number of cases & Cygb \\
\hline $\begin{array}{c}\text { Control group } \\
\text { Observation } \\
\text { group (I) }\end{array}$ & 20 & $0.472 \pm 0.096$ \\
$\begin{array}{c}\text { Observation } \\
\text { group (II) }\end{array}$ & 20 & $0.541 \pm 0.094$ \\
$\begin{array}{c}\text { Observation } \\
\text { group (III) }\end{array}$ & 20 & $0.769 \pm 0.103$ \\
$\begin{array}{c}\text { Observation } \\
\text { group (IV) }\end{array}$ & 20 & $1.014 \pm 0.090$ \\
\hline
\end{tabular}

Effects of hypobaric hypoxia on myocardial mitochondrial MDA levels in volleyball players It can be known from statistical comparison that compared with the control group, the levels of myocardial mitochondrial MDA in the observation group were significantly lower than those in the control group $(\mathrm{P}<0.05, \mathrm{t}=2.8676)$. See Table 3 for details.

Table 3 Effects of hypobaric hypoxia on myocardial mitochondrial MDA levels in volleyball players

\begin{tabular}{ccc}
\hline Group & Number of cases & $\begin{array}{c}\text { MDA } \\
(\mathrm{nmol} / \mathrm{mg})\end{array}$ \\
\hline $\begin{array}{c}\text { Control group } \\
\text { Observation } \\
\text { group }\end{array}$ & 20 & $3.1341 \pm 0.8463$ \\
$\mathrm{t}$ & 80 & $4.2750 \pm 1.7232$ \\
$\mathrm{P}$ & - & 2.8676 \\
\hline
\end{tabular}

\section{Effects of Hypobaric Hypoxia on Myocardial Mitochondrial ATP Level in Volleyball Players}

It can be known from statistical comparison that compared with the control group, the myocardial mitochondrial ATP level in the observation group was significantly lower than that in the control group $(\mathrm{P}<0.05, \mathrm{t}=6.4589)$. See Table 4 for details.

Table 4 Effects of Hypobaric Hypoxia on Myocardial Mitochondrial ATP Level in Volleyball Players

\begin{tabular}{ccc}
\hline Group & Number of cases & ATP $(\mathrm{ng} / \mathrm{mg})$ \\
\hline Control group & 20 & $260.8065 \pm 66.9083$ \\
Observation & 80 & $178.4334 \pm 46.385$ \\
group & & \\
$\mathrm{t}$ & - & 6.4589 \\
$\mathrm{P}$ & - & $<0.05$ \\
\hline
\end{tabular}

\section{Discussion}

\section{Effects of Hypobaric Hypoxia on SOD and CAT in Brain Tissue of Volleyball Players}

In healthy cells, SOD is the first line of defense for the free radical scavenging system, which effectively converts $\mathrm{O}_{2}$ to $\mathrm{H}_{2} \mathrm{O}_{2}$, and as the second line of defense for the removal of the system, the purpose is to remove the $\mathrm{H} 2 \mathrm{O} 2$ produced in the first line of defense. When the two combined, the body of free radicals in order to achieve a stable dynamic balance. Therefore, SOD and CAT is an important indicator of the detection of free radicals[10-11].

Once the body in a low-pressure hypoxia state, free radicals increased rapidly, triggering chain 
lipid peroxidation reaction and produce MDA, and then damage the cell membrane. With the increase in MDA, the greater the degree of brain damage. Therefore, control of SOD and CAT levels is the key to detecting changes in athlete signs under hypobaric hypoxia. In this study, as shown in Table 1, the levels of SOD and CAT in the volleyball group were significantly changed after low-pressure hypoxia training: the SOD and CAT levels in the observation group were significantly lower than those in the control group, $\mathrm{P}<0.05$ The Therefore, the level of oxygen free radicals in the observation group was significantly higher than that in the control group, the level of MDA was significantly increased and the degree of brain tissue damage was greater than that of the control group. (I), ( II ), (III) and (IV) were observed in the observation group (I), and the levels of SOD and CAT decreased with the prolongation of low-pressure hypoxia training time. SOD level was $(123.416 \pm 9.118)(\mathrm{U} / \mathrm{mg})$, which was significantly higher than that of observation group $(95.541 \pm 6.652)(\mathrm{U} / \mathrm{mg}), \mathrm{P}<0.05$; CAT $(30.155 \pm(\mathrm{U} / \mathrm{g})$, which was significantly higher than that of observation group $(10.329 \pm 2.254)(\mathrm{U} / \mathrm{g}), \mathrm{P}<0.05$. The levels of myocardial mitochondrial MDA in the observation group were significantly higher than those in the control group $(\mathrm{P}<0.05, \mathrm{t}$ $=2.8676$ ) (Table 3). Therefore, through this study can prove that low-pressure hypoxia can lead to volleyball players free radical scavenging system is broken, and then cause brain tissue damage[12]. 3.2 Effects of Hypobaric Hypoxia on Cygb Expression in Brain Tissue of Volleyball Players

As a kind of globulin, Cygb can store and transport oxygen, its level can directly reflect the oxygen content of brain tissue. If the expression of Cygb was detected in the brain tissue, there was hypoxia in the brain tissue. Another study found that with the prolongation of cerebral hypoxia, Cygb expression levels gradually increased. In the present study, the level of Cygb expression in the control group was $(0.472 \pm 0.096),(0.541 \pm 0.094)$ in the observation group and $(0.769 \pm 0.103)$ in the observation group, $(\mathrm{P}<0.05)$. The expression of $\mathrm{Cygb}$ in the observation group was higher than that in the control group ( $\mathrm{P}<0.05)$. The expression of Cygb in the observation group was higher than that in the control group $(1.06 \pm 0.090))$ And $(I V)$. The expression of Cygb in observation group (IV) was the highest $(\mathrm{P}<0.05)$. Thus, Cygb as a nuclear transcription factor into the nucleus, and thus the expression of other genes has had an impact.

\section{References}

[1] Witney L. Fewer anchors achieve successful arthroscopic shoulder stabilization surgery; 114 patients with 4 years of follow-up. J Shoulder Elbow Surg 2014; 23: 382-387.

[2] Ji LL, Fu RG, Mitchell EW, Griffiths M, Waldrop TG, Swartz HM (1994) Cardiac hypertrophy alters myocardial response to ischaemia and reperfusion in vivo. Acta Physiol Scand 151:279-290

[3] Kehrer JP, Lund LG (1994) Cellular reducing equivalents and oxidative stress. Free Radic Biol Med 17:65-75

[4] Laemmli UK (1970) Cleavage of structural proteins during the assembly of the head of bacteriophage T4. Nature 227:680-685

[5] Locke M, Noble EG, Tanguay RM, Feild MR, Ianuzzo SE, Ianuzzo CD (1995) Activation of heat-shock transcription factor in rat heart after heat shock and exercise. Am J Physiol 268:C1387-C1394 